\title{
Neuroinflammatory Markers in Spontaneously Hypertensive Rat Brain: An Immunohistochemical Study
}

\author{
Seyed K. Tayebati ${ }^{1 *}$, Daniele Tomassoni ${ }^{2}$ and Francesco Amenta ${ }^{1}$ \\ ${ }^{I}$ School of Medicinal Sciences and Health Products, via Madonna delle Carceri, 9, University of Camerino, Camerino, \\ Italy \\ ${ }^{2}$ School of Bioscience and Veterinary Medicine, Via Gentile III Da Varano, University of Camerino, Camerino, Italy
}

\section{A R T I C L E H I S T O R Y \\ Received: March 02, 2016 Revised: May 03, 2016 Accepted: May 26, 2016 DOI: $10.2174 / 18715273156661605271550$}

\begin{abstract}
Background: Spontaneously hypertensive rats (SHR) represent a model of hypertension and vascular injury. In the past decade, SHR were also considered as a model of vascular dementia. Several studies have shown that cerebrovascular changes in SHR may mimic brain vascular diseases of hypertensive individuals. Vascular and cerebrovascular changes during hypertension are often linked to inflammatory processes. Inflammation frequently affects vascular endothelium, perivascular astrocytes that form blood brain barrier. This inflammatory reaction may lead to neuro-inflammation with consequent damage of brain tissue. A significant brain atrophy, a reduction of white matter volumes, and BBB dysfunction were found in SHR. Micro- and macrogliosis in deep cortical regions were also observed. Based on these findings, this study was designed to define neuroinflammation entity in SHR, using immunohistochemistry technique for different inflammatory markers.
\end{abstract}

Methods: Thirty-two-week-old SHR and age-matched Wistar Kyoto rats were used. Brain was processed for immunohistochemistry. Astrogliosis markers for astrocytes (glial fibrillary acidic protein) and microglia (isolectin IB4) were used. The pro-inflammatory interleukins (IL-1b, IL-6) and tumor necrosis factor alpha (TNFa) expression were also evaluated.

Results: In SHR brain, an obvious glial reaction was found both for GFAP-immunoreactive astrocytes and for microglia. The pro-inflammatory IL-1b was significantly increased in CA1 sub-field of SHR hippocampus. The TNFa expression was higher in frontal cortex of SHR compared to WKY.

Conclusion: The above neuromorphological evidences indicate that SHR are predictive animal models for vascular brain disorders and neuroinflammation. Furthermore, this model may be useful to evaluate anti-inflammatory and neuroprotective effects of different molecules.

Keywords: Animal Models, Immunohistochemistry, Morphological Analysis, Neuroinflammation, Spontaneously Hypertensive Rat.

\section{INTRODUCTION}

Hypertension is an endemic health challenge of industrialized countries where diet, life style and stress relentlessly contribute to its development [1]. Currently, the pharmaceutical industry, using different chemical compounds, being created in medicinal chemistry labs through pharmaceutical research and innovation, is trying to manage this insidious and sly disorder. Many people around

*Address correspondence to this author at the School of Medicinal Sciences and Health Products, University of Camerino, Via Madonna delle Carceri, 9 62032 Camerino (MC), Italy; Tel: +39 0737 403305; Fax: +39 0737 403325; E-mail. khosrow.tayebaty@unicam.it the world remain oblivious of the fact they suffer from hypertension and its related complications. A large segment of the population has never tried to measure or control their blood pressure. Therefore, they do not know their predisposition to cardiovascular and other diseases. All of these risk factors lead to an important pathology that involves different organs (e.g. heart, kidney and brain) [2].

Among other features of hypertension, its role as an inflammatory cause is quite controversial. Different data suggest that inflammation is involved in the pathogenesis of hypertension [3]. In fact, it was discovered that the presence of $\mathrm{T}$ lymphocytes and other immunological cells in the kidneys and peripheral vasculature contributes to the end 
organ damage associated with this disease in animal model of hypertension [4].

In some model of mice knockout for RAG-1-1-, it was observed that the $\mathrm{T}$ cells play an important role in the genesis of hypertension [5]. RAG- $1^{-/-}$mice lacking $\mathrm{T}$ and $\mathrm{B}$ cells demonstrated a reduced blood pressure increase due to both angiotensin II infusion and deoxycorticosterone acetate plus sodium chloride (DOCA-salt) hypertension [5]. It should be highlighted that in this model, the circulating angiotensin II levels are suppressed [6]. There are clear evidence that angiotensin II increases the expression of CD69. This molecule is involved in lymphocyte proliferation and works as a signal-transmitting receptor in lymphocytes [e.g., natural killer (NK) cells] [7]. In addition, CD69 represents an early marker of $\mathrm{T}$ cell activation.

The effects of hypertension on brain is largely studied [8, 9]. The brain represents one of the principal organs damaged by hypertension [10]. Different cerebrovascular disorders due to hypertension lead to neural damages in some patients with stroke.

Spontaneously hypertensive rats (SHR) represent an excellent model of human hypertension $[11,12]$. They have been studied in over 20.000 papers since 1969 (data from Pubmed). This animal model, as other animal model of diseases, may not be an exact overlap to human disease, but it has a great advantage to represent a genetic type of hypertension [11]. Different organ damages due to hypertension were analyzed in SHR. Heart, renal, retinal, and cerebral alterations are among these aberrations $[11,13$, 14]. However, in each one of these areas, the vessel damage represents a principal cause of organ injury [14].

The hypertension correlation with inflammation is rather controversial. In a recent study, the authors have analyzed the effects of some important risk factor (e.g. obesity) on brain inflammation. They concluded that the obesity as other risk factors leads to brain inflammation that may be translated in an abnormal activation of sympathetic nervous system and in the last phase, may lead to neurogenic hypertension [15].

However, many other authors affirm that hypertension damages the vessel endothelium and some inflammatory events could be revealed.

In this work, using immunohistochemistry technique to identify different inflammatory markers in SHR brain and control Wistar Kyoto (WKY), the appropriateness of this model to evaluate the neuroinflammation due to hypertension was studied.

\section{MATERIALS AND METHODS}

Thirty-two-week-old male SHR (404.2 $\pm 22.8 \mathrm{~g}, \mathrm{n}=6)$ and age-matched WKY rats $(406.8 \pm 65.7 \mathrm{~g}, \mathrm{n}=6)$ were used. Each cage housed two animals (size $26 \times 41 \mathrm{~cm}$ ) and placed in the experimental room for acclimatization $24 \mathrm{~h}$ before testing. The animals were fed with standard laboratory diet and with tap water ad libitum, and kept at $23 \pm 1{ }^{\circ} \mathrm{C}$ with a 12 $\mathrm{h}$ light/dark cycle, light at 7 a.m. Animal manipulations were carried out according to the National and European
Community Guidelines for Animal Care (DL 116/92, of application of the European Communities Council Directive 86/609/EEC and Directive 2010/63/EU) and of ethical guidelines of the University of Camerino. All efforts were made to minimize animal suffering and to reduce the number of animals used.

Before their death, animals were anaesthetised with pentobarbital sodium $(50 \mathrm{mg} / \mathrm{kg}$, i.p.) and then were decapitated. The brain was removed from skull, washed, weighed, fixed in a Histochoice solution and embedded in semi-synthetic paraffin. Serial sagittal consecutive $8 \mu \mathrm{m}$ thick sections from lateral 1,40 to $2,40 \mathrm{~mm}$ were stained with Nissl's method (cresyl violet 1.5\%) for assessing the occurrence of relevant microanatomical changes.

\section{Immunohistochemistry}

Serial consecutive sagittal sections were processed for immunohistochemistry to detect GFAP as a marker of astroglial reaction, IL-1 $\beta$, IL-6 and TNF- $\alpha$ as proinflammatory markers.

The $1^{\text {st }}, 6^{\text {th }}, 11^{\text {th }}, 16^{\text {th }}$, and $21^{\text {st }}$ consecutive sections were processed for GFAP immunohistochemistry using a mouse serum against GFAP as detailed in Table 1.

The $2^{\text {nd }}, 7^{\text {th }}, 12^{\text {nd }}, 17^{\text {th }}$ and $22^{\text {th }}$ consecutive sections were processed for Il-1 $\beta$ immunohistochemistry by exposing them to a polyclonal antibody raised against IL-1 $\beta$.

The $3^{\text {rd }}, 8^{\text {th }}, 13^{\text {th }}, 18^{\text {th }}$ and $23^{\text {th }}$ consecutive sections were processed for IL-6 immunohistochemistry (Table 1) and the $4^{\text {th }}, 9^{\text {th }}, 14^{\text {th }}, 19^{\text {th }}$ and $24^{\text {th }}$ were used for immunohistochemical detection of TNF $\alpha$ (Table 1). To test the specificity of different primary antibodies the $5^{\text {th }}, 10^{\text {th }}$, $15^{\text {th }}, 20^{\text {th }}$ and $25^{\text {th }}$ were used as control sections and exposed to a non-immune IgG instead of the primary antibody. Another group of consecutive section was used for lectin histochemistry using Lectin from Bandeiraea simplicifolia (Griffonia simplicifolia) Isolectin B4 (BSI-B4) peroxidase conjugated, (Cat. No. L5391 SIGMA. Sigma-Aldrich, St. Louis, MO, USA).

After re-hydration, sections were incubated with Tris$\mathrm{HCl} 20 \mathrm{mM}$, EDTA $0,65 \mathrm{mM}$ Tween $200,0005 \% \mathrm{pH} 9$, in a microwave for $5 \mathrm{~min}$ (two times) for antigen retrieval.

Sections used for immunohistochemistry after a preincubation in 3\% PBS-bovine serum albumin for $1 \mathrm{~h}$, they were exposed overnight in a moist chamber at $4^{\circ} \mathrm{C}$ to primary antibodies (Table 1) and then for $30 \mathrm{~min}$ at $25^{\circ} \mathrm{C}$ to corresponding secondary biotinylated antibodies (Table 1) diluted to 1:200. After incubation for $30 \mathrm{~min}$ with AvidinBiotin-Complex (VECTASTAIN ABC Kit, Vector laboratories, Burlingame, $\mathrm{Ca}$, USA). The product of immune reaction was revealed using 3,3'-diaminobenzidine as a chromogen (Peroxidase Substrate Kit, Vector laboratories, Burlingame, $\mathrm{Ca}$, USA).

For isolectin B4 (IB4) histochemistry, after preincubation with $3 \% \quad \mathrm{H}_{2} \mathrm{O}_{2}$ the sections were incubated overnight with a solution of isolectin in PBS diluted 1:100. The isolectin binding staining was revealed using 3,3'diaminobenzidine as a substrate (Peroxidase Substrate Kit, Vector laboratories, Burlingame, $\mathrm{Ca}, \mathrm{USA}$ ). 
Table 1. Antibodies and concentration used in immunohostochemistry protocol.

\begin{tabular}{|c|c|c|c|c|c|}
\hline Primary Antibody & $\begin{array}{c}\text { Primary Antibody } \\
\text { Dilution }\end{array}$ & $\begin{array}{l}\text { Primary Antibody } \\
\text { Company }\end{array}$ & Secondary Antibody & $\begin{array}{l}\text { Secondary Antibody } \\
\text { Dilution }\end{array}$ & $\begin{array}{l}\text { Secondary Antibody } \\
\text { Company }\end{array}$ \\
\hline $\begin{array}{l}\text { GFAP (clone GA5) } \\
\text { Mouse moloclonal }\end{array}$ & $1: 500$ & $\begin{array}{l}\text { Chemicon Millipore, } \\
\text { Cat. No. } 3402\end{array}$ & $\begin{array}{l}\text { Biotinylated anti- } \\
\text { mouse IgG }\end{array}$ & $1: 200$ & Bethyl company \\
\hline $\begin{array}{l}\text { IL-1及(H-153)) rabbit } \\
\text { polyclonal IgG }\end{array}$ & $1: 50$ & $\begin{array}{c}\text { Santa Cruz } \\
\text { Biotechnology } \\
\text { Cat. No. SC-7884 }\end{array}$ & $\begin{array}{l}\text { Biotinylated anti- } \\
\text { rabbit IgG }\end{array}$ & $1: 200$ & Bethyl company \\
\hline $\begin{array}{l}\text { IL-6 (M-19) goat } \\
\text { polyclonal IgG }\end{array}$ & $1: 50$ & $\begin{array}{c}\text { Santa Cruz } \\
\text { Biotechnology } \\
\text { Cat. No. SC-1265 }\end{array}$ & $\begin{array}{l}\text { Biotinylated anti-goat } \\
\text { IgG }\end{array}$ & $1: 200$ & Bethyl company \\
\hline $\begin{array}{l}\text { TNF- } \boldsymbol{\alpha} \text { rabbit } \\
\text { polyclonal IgG }\end{array}$ & $1: 50$ & $\begin{array}{c}\text { Sigma Aldrich } \\
\text { Cat. No. SAB4502982 }\end{array}$ & $\begin{array}{l}\text { Biotinylated } \\
\text { anti-rabbit IgG }\end{array}$ & $1: 200$ & Bethyl company \\
\hline
\end{tabular}

The sections were counterstain with methyl green solution to identify neuronal bodies.

\section{Image Analysis}

Stained sections were viewed under a light microscope at a final magnification of $x 400$. Via a TV connection with a Nikon DS-Ri2 digital camera, images were analyzed using the Nikon Imaging Software Advanced Version (NIS Advanced System).

The area of astrocytes, considered as cells displaying a dark-brown GFAP immunoreactivity, was assessed using on overlap function of the NIS Advanced System. Morphometric data were then analyzed according to the protocol described in an earlier paper of our group [16]. The density of immunoreaction area occupied by proinflammatory cytokines was measured by image analysis in different brain area. The intensity of immunostaining developed in microdensitometrically by calibrating the image analyzer taking as "zero" the background developed in sections incubated with a non-immune serum and "250" as the conventional value of maximum intensity of staining.

The area occupied by isolectin IB4 reaction was measured in different fields, devoid of reactive blood vessels of frontal cortex and hippocampus. The data were expressed as percentage of area occupied by IB4 structures.

\section{Data Analysis}

Means of different parameters investigated were calculated from single animal data, and group means \pm S.E.M. were then derived from single animal values. The significance of differences between means was analyzed by analysis of variance (ANOVA) followed by the Student's t-test.

\section{RESULTS}

Body weight values were similar in normotensive WKY rats or SHR (data not shown). Systolic blood pressure values were higher in SHR rats $(210 \pm 7 \mathrm{mmHg})$ compared to the normotensive WKY rats $(132 \pm 9 \mathrm{mmHg})$. Brain weight values were significantly lower in $\operatorname{SHR}(2,01 \pm 0.03)$ than WKY $(2,16 \pm 0.05)$.
Sections processed for GFAP immunohistochemistry developed dark-brown astrocytes throughout frontal cortex and hippocampus. The immunoreaction shows an increase of the number-of and size of parenchymal astrocytes in SHR compared with age-matched WKY (Fig. 1). These findings confirm other data previously published $[12,17]$.
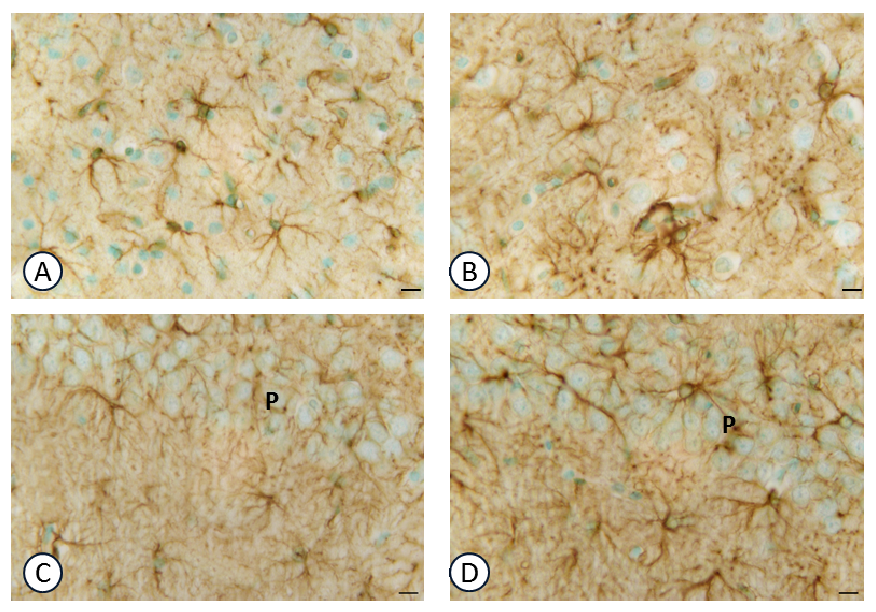

Fig. (1). Section of rat frontal cortex $(\mathbf{A}, \mathbf{B})$ and hippocampus $(\mathbf{C}$, D) processed for glial fibrillary acidic protein (GFAP) immunohistochemistry. A,C: WKY rats; B,D: SHR. P: Pyramidal layer. Calibration bar: $10 \mathrm{~mm}$.

Sections processed for IL-1 $\beta$ immunohistochemistry revealed dark-brown immunoreaction throughout brain areas investigated. The immunoreaction is localized in the extracellular spaces around the body of neurons in both WKY and SHR. No reaction was detected within the perikaryon of pyramidal neurons of frontal cortex and hippocampus (Fig. 2). In the frontal cortex, no difference in IL-1 $\beta$ expression was observed between WKY and SHR (Fig. 2). On the contrary, in the hippocampus, particularly in CA1 subfield, the increase of immunreation was evidenced in SHR compared to WKY (Fig. 2). This observation was confirmed by quantitative image analysis (Fig. 2).

No immunreaction for IL-6 was observed in different brain areas investigated (data not shown). The immunohistochemistry for TNF $\alpha$ was mainly localized in 

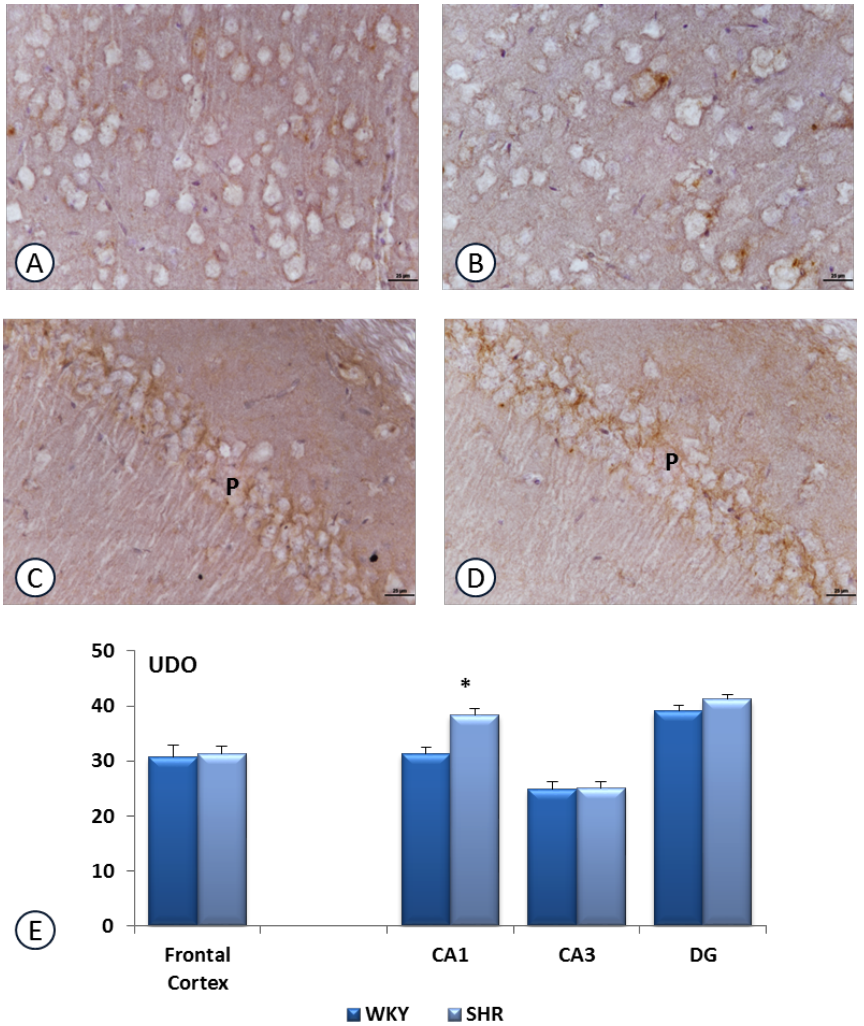

Fig. (2). Section of rat frontal cortex $(\mathbf{A}, \mathbf{B})$ and CA1 subfield of hippocampus, processed for Interleukin 1-beta (IL-1 b) immunohistochemistry. A,C: WKY rats ; B,D: SHR rats. P: Pyramidal layer. Calibration bar: $25 \mathrm{~mm}$. Panel E shows the density of immunoreaction for IL-1 b in different groups investigated. Data are expressed as arbitrary units of immunoreactions (UDO). Data are the means + S.E.M. ${ }^{*} \mathrm{p}<0.05$ vs WKY rats.

axon hillock of pyramidal neurons of frontal cortex and hippocampus. The immunoreaction was significantly increased in frontal cortex (Fig. 3) but not in hippocampus of SHR in comparison with WKY of the same age (Fig. 3).

In general, The IB4 binds the terminal $\alpha$-D-galactosyl residues and terminal $\mathrm{N}$-acetyl $\alpha-\mathrm{D}-\mathrm{D}$-galactosaminyl residues which are present in the wall of vessels and microglial cells [18].

The IB4 reaction revealed the presence of activated microglial cells in the white matter of hippocampus and frontal cortex of SHR (Fig. 4). The IB4 reaction area was increased in the white matter but not in gray matter of the different cerebral fields investigated (Figs. 4 and 5).

\section{DISCUSSION}

The last six decades have seen much study directed to arterial blood pressure [19]. Although there can be little doubt that simple palpation of the pulse was carried out by the early Egyptians [20] and the Yellow Emperor's Classic of Internal Medicine [21], current measurement of the pressure in parts of the circulation really started in the middle of the eighteenth century with the experiments of Stephen Hales (For historic case study see [22]). However,
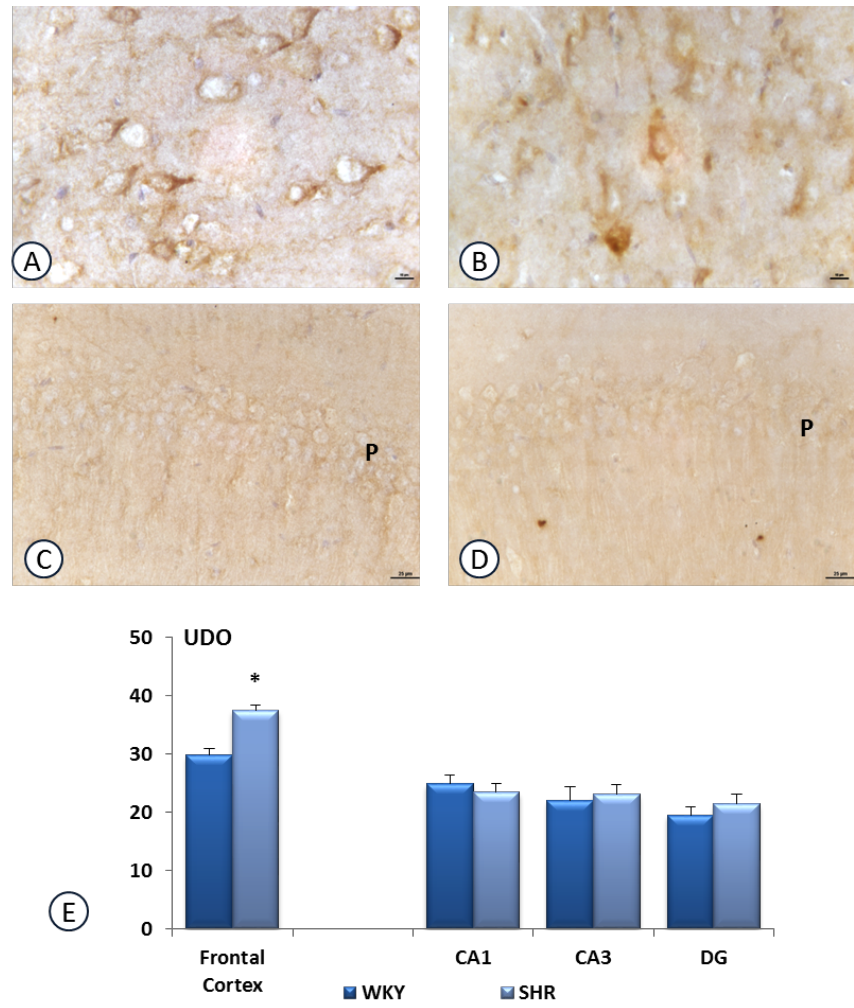

Fig. (3). Section of rat frontal cortex $(\mathbf{A}, \mathbf{B})$ and CA1 subfield of hippocampus $(\mathbf{C}, \mathbf{D})$, processed for Tumor Necrosis Factor alpha (TNFa) immunohistochemistry. A,C: WKY rats ; B,D: SHR rats. P: Pyramidal layer. Calibration bar for A and B: $10 \mathrm{~mm}$; calibration bar for C and D: $25 \mathrm{~mm}$. Panel $\mathrm{E}$ shows the density of immunoreaction for $\mathrm{TNFa}$ in different groups investigated. The data are expressed as arbitrary units of immunoreactions (UDO). Data are the means + S.E.M. ${ }^{*} \mathrm{p}<0.05$ vs WKY rats.

these ancient literature and methods demonstrate that the medical queries regarding blood pressure drew continuous attention and evolution. Probably, this medical problem has represented an important challenge from the dawn of time.

As previously mentioned, hypertension's involvement in inflammation and/or neuroinflammation is rather controversial. However, the concurrence of neuroinflammation and hypertension is clearly demonstrated [15, 23, 24].

Since 1965, the animal model of hypertension (Spontaneously hypertensive rat, SHR) was used to study different features (e.g. genesis, molecular, vascular, neural,...) of this systemic disorder. These animals have also represented the first "patients" which were treated with different antihypertensive drugs $[25,26]$. Therefore, because of the presence of a number of studies regarding this model, there is much information concerning the development and evolution of hypertension [27-29]. In particular, among these data, should be quoted spontaneous white matter damage, cognitive decline and neuroinflammation [23].

In this context, our previous studies and the present work has provided evidence for different inflammatory events occurring in SHR brain [12, 17, 29, 30]. Astrogliosis, and other effects of hypertension on cerebral tissue were also evaluated in different studies [23, 31, 32]. The image 

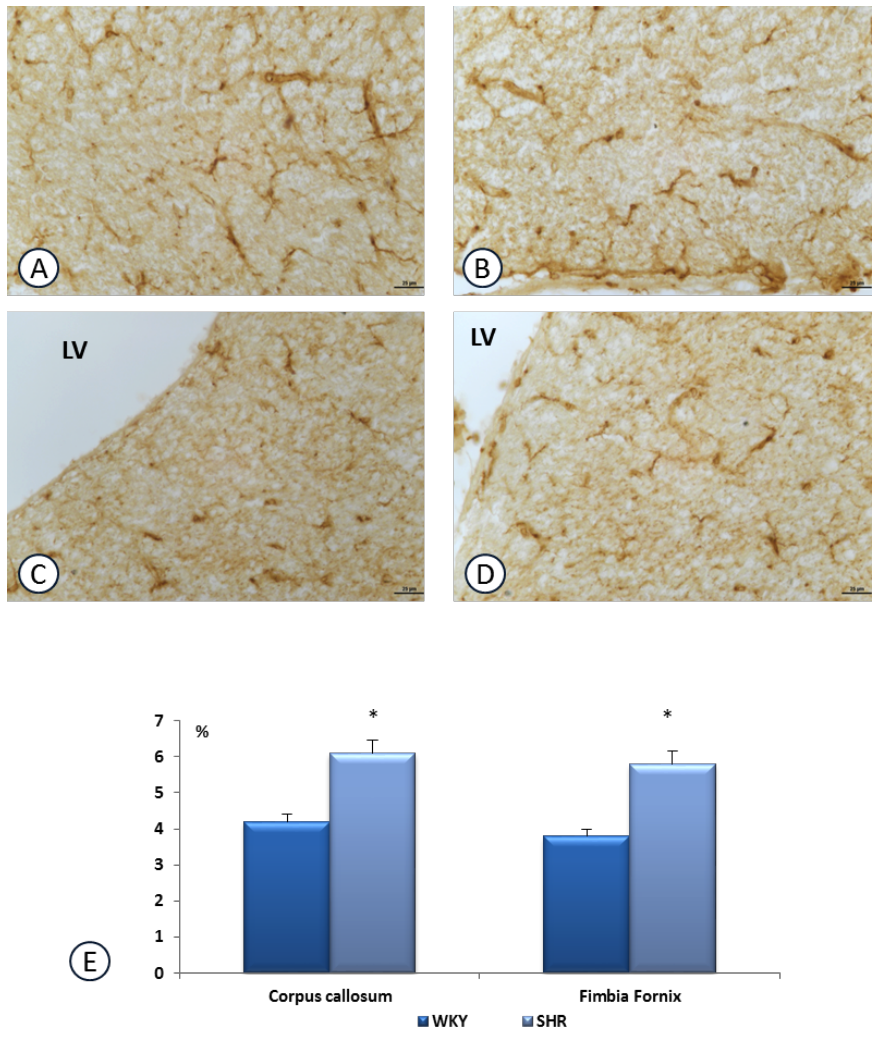

Fig. (4). Section of rat corpus callosum $(\mathbf{A}, \mathbf{B})$ and fimbria-fornix (C, D), processed for isolectin IB4 histochemistry. A, C: WKY rats; B,D: SHR rats. LV: lateral ventricle. Calibration bar: $25 \mathrm{~mm}$. Panel E shows the area occupied by isolectin reaction in an area of $0,5 \mathrm{~mm}^{2}$ (\% Area I.R.) of corpus callosum and fimbria fornix. Data are the means + S.E.M. ${ }^{*} \mathrm{p}<0.05$ vs WKY rats.

analysis of some cerebral areas that are relevant for cognition activities (frontal cortex and hippocampus), using antibodies against GFAP, IL-1 $\beta$, and TNF $\alpha$, have clearly established that the hypertension in SHR of 32-weeks increases both astrogliosis and inflammatory markers level. Furthermore, the microglial activation is evident in SHR in particular in white matter. Although the IB4 reaction is not selective for microglial cells because it also binds to the endothelial cells, demonstrating an increase in density of reaction related to a greater volume of microglial cells. This picture is in line with the literature regarding the presence of a considerable vessel and micro vessel damage in these regions [23, 31, 32]. Microvascular brain disorder is predominantly considered an outcome of large artery rigidity and increased pulse pressure. Furthermore, pulse pressure leads to a pulsatile stress in the microcirculation of high flow organs such as the brain. Therefore, this event induces wall hypertrophy and luminal diameter reduction of small vessels [33, 34]. Similar data concerning SHR brain micro vessels were published some years ago $[12,13,35]$. Other morphological data have provided evidence for a narrowing effect of hypertension on corpus callosum, and an enlarging effect on cerebral ventricles [36]. An accurate image analysis was also carried out on other pivotal areas for cognition as frontal cortex, temporal cortex and hippocampus [36]. In SHR, both cortical and hippocampal areas were significantly decreased [36].
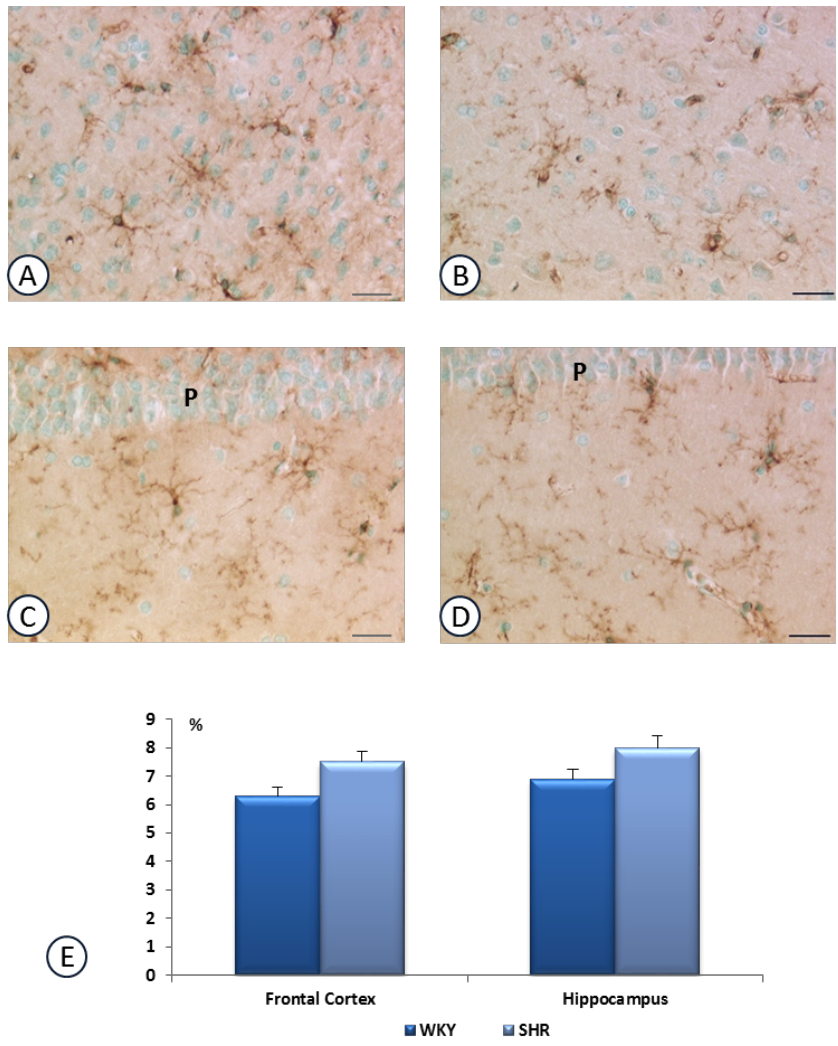

Fig. (5). Section of rat frontal cortex $(\mathbf{A}, \mathbf{B})$ and CA1 subfield of hippocampus, processed for processed for isolectin IB4 histochemistry. A, C: WKY rats; B, D: SHR rats. P: Pyramidal layer. Calibration bar: $25 \mathrm{~mm}$. Panel $\mathrm{E}$ shows the area occupied by isolectin reaction in an area of $0,05 \mathrm{~mm} 2$ (\% Area I.R.) of frontal cortex and CA1 hippocampus. Data are the means + S.E.M.

A pharmacological approach may be implemented to prevent neuroinflammation using antioxidant, antiinflammatory, anti-amyloidogenic, neuroprotective, and cognition-enhancing molecules including nutraceuticals [37]. Among other compounds, choline containing phospholipids could also be used, as they have demonstrated some antiinflammatory effects $[12,17]$. Therefore, more detailed studies concerning the use of these compounds in SHR, may be useful to understand neuroinflammatory processes due to hypertension and its treatment.

\section{CONCLUSION}

Gathering up, these findings together with previous data, it is possible to conclude that the SHR, having a normotensive control (WKY), accounts as an important and reproducible animal model concerning hypertension, and its correlated organ damage. subsequently, it may be used as a predictable model to detect the (neuro) inflammatory mechanisms of hypertension that involve micro vessels at the neurological level and other high flow organs.

\section{LIST OF ABBREVIATIONS}

$\begin{array}{ll}\mathrm{BBB} & =\text { Blood Brain Barrier } \\ \text { GFAP } & =\text { Glial Fibrillary Acidic Protein }\end{array}$ 


$$
\begin{aligned}
& \text { IL- } \beta=\text { Interleukin-1 Beta } \\
& \text { IL-6 = Interleukin-6 } \\
& \text { IB4 = Isolectin B4 } \\
& \text { NIS }=\text { Nikon Imaging Software Advanced Version } \\
& \text { SHR = Spontaneouysly Hypertensive Rat } \\
& \text { RAG-1 }{ }^{-/}=\text {Recombination-Activating Genes } \\
& \mathrm{TNF} \alpha=\text { Tumor Necrosis Fator Alpha } \\
& \text { WKY }=\text { Wistar Kyoto Rat }
\end{aligned}
$$

\section{REFERENCES}

[1] Kearney PM, Whelton M, Reynolds K, Muntner P, Whelton PK, He J. Global burden of hypertension: analysis of worldwide data. Lancet 2005; 365: 217-23.

[2] Chobanian AV. Shattuck Lecture. The hypertension paradox-more uncontrolled disease despite improved therapy. N Engl J Med 2009; 361: 878-87.

[3] Coffman TM. Under pressure: the search for the essential mechanisms of hypertension. Nat Med 2011; 17:1402-9.

[4] Muller DN, Mervaala EM, Schmidt F, et al. Effect of bosentan on NF-kappaB, inflammation, and tissue factor in angiotensin IIinduced end-organ damage. Hypertension 2000; 36: 282-90.

[5] Guzik TJ, Hoch NE, Brown KA, et al. Role of the T cell in the genesis of angiotensin II induced hypertension and vascular dysfunction. J Exp Med 2007; 204: 2449-60.

[6] Paton JF, Raizada MK. Neurogenic hypertension. Exp Physiol 2010; 95: 569-71

[7] Cambiaggi C, Scupoli MT, Cestari T, et al. Constitutive expression of CD69 in interspecies T-cell hybrids and locus assignment to human chromosome. Immunogenetics 1992; 36: 117-20.

[8] Rubattu S, Pagliaro B, Pierelli G, et al. Pathogenesis of target organ damage in hypertension: role of mitochondrial oxidative stress. Int J Mol Sci 2014; 16: 823-39.

[9] Pires PW, Dams Ramos CM, Matin N, Dorrance AM. The effects of hypertension on the cerebral circulation. Am J Physiol Heart Circ Physiol 2013; 304: H1598-614.

[10] Scott JA, Braskie MN, Tosun D, et al. Cerebral Amyloid and Hypertension are Independently Associated with White Matter Lesions in Elderly. Alzheimer's Disease Neuroimaging Initiative. Front Aging Neurosci 2015; 7: 221.

[11] Kato T, Mizuguchi N, Ito A. Blood pressure, renal biochemical parameters and histopathology in an original rat model of essential hypertension (SHRSP/Kpo strain). Biomed Res 2015; 36: 169-77.

[12] Tayebati SK, Amenta F, Tomassoni D. Cerebrovascular and bloodbrain barrier morphology in spontaneously hypertensive rats: effect of treatment with choline alphoscerate. CNS Neurol Disord Drug Targets 2015; 14: 421-9.

[13] Tayebati SK, Tomassoni D, Amenta F. Spontaneously hypertensive rat as a model of vascular brain disorder: microanatomy, neurochemistry and behavior. J Neurol Sci 2012; 322: 241-9.

[14] Meazza R, Scardino C, Di Palma GL, et al. Target organ damage in hypertensive patients: correlation between retinal arteriovenular ratio and left ventricular geometric patterns. J Hum Hypertens 2014; 28: 274-8.

[15] Winklewski PJ, Radkowski M, Wszedybyl-Winklewska M, Demkow U. Brain inflammation and hypertension: the chicken or the egg? J Neuroinflammation 2015; 12: 85 .

[16] Sabbatini M, Catalani A, Consoli C, Marletta N, Tomassoni D, Avola R. The hippocampus in spontaneously hypertensive rats: an animal model of vascular dementia? Mech Ageing Dev 2002; 123: $547-59$.
Tayebati SK, Di Tullio MA, Tomassoni D, Amenta F. Neuroprotective effect of treatment with galantamine and choline alphoscerate on brain microanatomy in spontaneously hypertensive rats. J Neurol Sci 2009; 283: 187-94.

Hayes CE, Goldstein IJ. An alpha-D-galactosyl-binding lectin from Bandeiraea simplicifolia seeds. Isolation by affinity chromatography and characterization J Biol Chem 1974; 249: 1904-14.

Ruskin A. Classics in arterial hypertension. Springfield IL: Charles C Thomas Publisher, 1956.

Gispen JGW. Measuring" the patient in ancient Egyptian medical texts. Janus $1957 ;$ 54: 224-7.

N. Yellow emperor's classic of internal medicine. Books 29, published between 2698 and 2598 B.C.

[23] Kaiser D, Weise G, Möller K, et al. Spontaneous white matter damage, cognitive decline and neuroinflammation in middle-aged hypertensive rats: an animal model of early-stage cerebral small vessel disease. Acta Neuropathol Commun 2014; 2: 169.

[24] Nguyen JC, Killcross AS, Jenkins TA. Obesity and cognitive decline: role of inflammation and vascular changes. Front Neurosci 2014; 8: 375

[25] Sabbatini M, Tomassoni D, Amenta F. Influence of treatment with $\mathrm{Ca}(2+)$ antagonists on cerebral vasculature of spontaneously hypertensive rats. Mech Ageing Dev 2001; 122: 795-809.

[26] Sabbatini M, Tomassoni D, Amenta F. Hypertensive brain damage: comparative evaluation of protective effect of treatment with dihydropyridine derivatives in spontaneously hypertensive rats. Mech Ageing Dev 2001; 122: 2085-105.

[27] Okamoto K, Aoki K. Development of a strain of spontaneously hypertensive rats. Jpn Circ J 1963; 27: 282-93.

[28] Lundin S, Herlitz H, Hallbäck-Nørdlander M, Ricksten SE, Göthberg G, Berglund G. Sodium balance during development of hypertension in the spontaneously hypertensive rat (SHR). Acta Physiol Scand 1982; 115: 317-23.

[29] O'Brien MD, Halsey JH Jr, Strong ER. The effect of hypertension on ischemic cerebral edema in spontaneously hypertensive rats. Neurol Res 1983; 5: 83-93.

[30] Tomassoni D, Bramanti V, Amenta F. Expression of aquaporins 1 and 4 in the brain of spontaneously hypertensive rats. Brain Res 2010; 1325: 155-63.

[31] Tomassoni D, Amenta F, Amantini C, et al. Brain activity of thioctic Acid enantiomers: in vitro and in vivo studies in an animal model of cerebrovascular injury. Int J Mol Sci 2013; 14: 4580-95.

[32] Tomassoni D, Avola R, Di Tullio MA, Sabbatini M, Vitaioli L, Amenta F. Increased expression of glial fibrillary acidic protein in the brain of spontaneously hypertensive rats. Clin Exp Hypertens 2004; 26: 335-50.

[33] Scuteri A, Nilsson PM, Tzourio C, Redon J, Laurent S. Microvascular brain damage with aging and hypertension: pathophysiological consideration and clinical implications. J Hypertens 2011; 29: 1469-77

[34] Mitchell GF. Effects of central arterial aging on the structure and function of the peripheral vasculature: implications for end-organ damage. J Appl Physiol 2008; 105: 1652-60.

[35] Sabbatini M, Bellagamba G, Casado A, Tayebati SK, Venarucci D, Amenta F. Protective effect of treatment with nicardipine on cerebrovascular tree of spontaneously hypertensive rats. Clin Exp Hypertens 2001; 23: 143-55.

[36] Sabbatini M, Baldoni E, Cadoni A, Vitaioli L, Zicca A, Amenta F. Forebrain white matter in spontaneously hypertensive rats: a quantitative image analysis study. Neurosci Lett 1999; 265: 5-8.

[37] Venigalla M, Sonego S, Gyengesi E, Sharman MJ, Münch G. Novel promising therapeutics against chronic neuroinflammation and neurodegeneration in Alzheimer's disease. Neurochem Int 2016; 95: 63-74. 